\title{
Usefulness of examination of palmar creases for assessing severity of anemia in Indian perspective: A study from a tertiary care center
}

\section{Gouranga Santra}

Department of Medicine, Midnapore Medical College, Paschim Medinipur, West Bengal,

India

Address for the Correspondence:

Dr. Gouranga Santra Block-P, Flat-306, Binayak Enclave, 59 Kalicharan Ghosh Road, Kolkata, - 700 050,

West Bengal, India.

E-mail: g.santra@yahoo.com

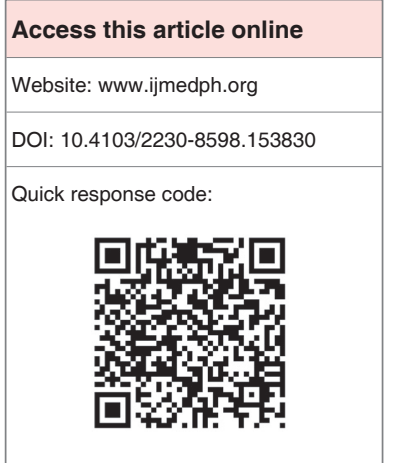

Background and Objectives: Palmar creases may become as pale as the surrounding skin in severe anemia. However, its sensitivity for assessing severe anemia is questionable, especially in Indian perspective. The study was conducted to evaluate the value of palmar creases in detecting severe anemia. Materials and Methods: Patients with laboratory confirmed anemia were assessed for pallor of palmar creases without information of patient's hemoglobin $(\mathrm{Hb})$ value to the observer. Sensitivity and specificity of palmar creases pallor were assessed for severe anemia. Role of clinical signs such as severe pallor of conjunctiva, tongue and nail-beds and pulmonary ejection systolic murmur were also assessed for predicting severe anemia. Results: Of 200 patients, 50 had severe anemia $(\mathrm{Hb}<7 \mathrm{~g} / \mathrm{dL})$. Only six patients with $\mathrm{Hb}<7 \mathrm{~g} / \mathrm{dL}$ were found to have creases looking similar pale to surrounding skin. Average $\mathrm{Hb}$ level of them was $4.05 \pm 0.82 \mathrm{~g} / \mathrm{dL}$. No patients with $\mathrm{Hb} \geq 7 \mathrm{~g} / \mathrm{dL}$ had pale palmar creases. In severely anemic patients, its sensitivity is only $12 \%$, but specificity is $100 \%$, and positive likelihood ratio is $>1200$. Severe pallor of conjunctiva, tongue and nail-beds and pulmonary ejection systolic murmur were more sensitive, but specificity of them was less for severe anemia. Conclusions: Color of palmar creases is a poorly sensitive indicator of the severe anemia especially in Indians due to the pigmentation of creases. Hence, the absence of palmar crease pallor is not likely to be of use in ruling out severe anemia.

Key words: Conjunctiva, hemoglobin, nail-bed, pallor, tongue

\section{INTRODUCTION}

Palmar creases give a clue to the degree of anemia. When they are as pale as the surrounding skin, the patients usually have severe anemia, a hemoglobin $(\mathrm{Hb})$ level $<7 \mathrm{~g} / \mathrm{dL} .{ }^{[1]}$ But there is a necessity to reconsider this concept in Indian perspective because of pigmentation of the skin and palmar creases in Indians. Palmar creases are helpful for detecting severe anemia when examination of other anatomical sites is problematic in the presence of conjunctivitis, glossitis or nail dystrophy. In contrary, pigmentation disorders (like vitiligo, Addison's disease) and dermatitis of hands may prevent assessment of palmar crease pallor. Different studies showed that palmar crease pallor has high specificity for severe anemia, but sensitivity of it is low. ${ }^{[2,3]}$ Examination of palmar creases as the severity marker of anemia is cost-effective and easy way to assess patients at busy out-patient clinic or at community programs. Possibility of palmar creases to be as pale as the surrounding skin is high in fair skinned western population. As Indians are darker/more pigmented than western population, palmar crease pallor may be less effective as a marker of severe anemia. So we conducted a study to evaluate the significance of examining the palmar creases as an indicator of severe anemia in Indian perspective. The study also included other clinical signs for assessing severe anemia like severe pallor of conjunctiva, tongue and nail-beds and pulmonary ejection systolic murmur.

\section{MATERIALS AND METHODS}

We selected laboratory confirmed anemic patients randomly with age $\geq 15$ years attending out-patient clinic or admitted in the indoor of Medicine department for different diseases. The study was conducted over 4 months period (May-September, 2014). Totally 200 patients were included for the study. Patients 
with $\mathrm{Hb}$ level $<12 \mathrm{~g} / \mathrm{dL}$ for female and $<13 \mathrm{~g} / \mathrm{dL}$ in male were selected for study. ${ }^{[4]} \mathrm{Hb}$ level $<7 \mathrm{~g} / \mathrm{dL}$ was considered severe anemia for all patients for this study (considering the prevailing concept of $\mathrm{Hb}$ level $<7 \mathrm{~g} / \mathrm{dL}$ associated with palmar crease pallor) instead of WHO recommended value $<8 \mathrm{~g} / \mathrm{dL}$ for adult males and females and $<7 \mathrm{~g} / \mathrm{dL}$ for pregnant women. ${ }^{[4]}$ Color of palmar creases of all 200 patients was assessed by a physician who had no knowledge of $\mathrm{Hb}$ level of the patients. Pallor of palmar creases was seen with hyperextending fingers and stretching skin on either side of the creases. Patients with $\mathrm{Hb} \%<7 \mathrm{~g} / \mathrm{dL}$ and patients with $\mathrm{Hb} \geq 7 \mathrm{~g} / \mathrm{dL}$, but $<12 \mathrm{~g} / \mathrm{dL}$ in female or $<13 \mathrm{~g} / \mathrm{dL}$ in male were compared for presence of palmar crease pallor. Other clinical signs like severe pallor of conjunctiva, tongue and nail-beds and pulmonary ejection systolic murmur were also assessed to correlate their predictability to diagnose severe anemia. Pallor on conjunctiva, tongue, and nail-beds, and pulmonary ejection systolic murmur were assessed by four other physicians separately. Patients with pigmentation disorders such as vitiligo, albinism, contact dermatitis of hands, scarring of palms, Addison's disease, thyrotoxicosis, and myxedema were excluded from the study. Chronic liver disease (CLD) patients were excluded for possibility of palmar erythema. Patients with conjunctivitis, glossitis, onycholysis, use of nail polish, valvular and congenital heart diseases were excluded from the study for better assessment of respective anatomic areas for signs of anemia. Patients with fever, bradycardia (large stroke volume), and pregnancy were excluded to rule out the chance of other causes of flow murmur rather than severe anemia. The study was conducted in accordance with the ethical standards of the responsible committee on human experimentation (institutional and national) and with the Helsinki Declaration of 1975, as revised in 2008. Ethical Committee permission was taken. Informed consent was taken from all patients for being included in the study.

\section{Statistical analysis}

Simple statistical methods are used for data analysis including the mean value, percentages, standard deviation (SD). GraphPad QuickCalcs online statistical calculator was used for data analysis (www.graphpad.com/quickcalcs/). Sensitivity, specificity and likelihood ratio were used for assessing accuracy and usefulness of clinical signs for detecting severe anemia. ${ }^{[5]}$

\section{RESULTS}

Initially, total number of patients selected was 208. However, eight patients were excluded from the study. One patient had contact dermatitis of hands. One had vitiligo involving the palms. One case had CLD with palmar erythema, and another case had Addison's disease with hyper-pigmentation of palmar creases. One patient had conjunctivitis, two had glossitis and one had rheumatic heart disease. All these co-morbidities prevent assessment of clinical signs of pallor of respective anatomic sites. Hence, finally 200 patients were assessed. Demographic profile of the patients including sex, socioeconomic status, education, skin complexion, professions was tabulated in Table 1. Frequencies of different diseases with severe anemia or mild-moderate anemia and number of patients

\begin{tabular}{lc} 
Table 1: Demographic profile of the patients \\
\hline Parameters & Values \\
\hline Age & $36.08 \pm 12.84(\mathrm{SD})$ years \\
Male: female & $121: 79$ \\
Hindu: muslim & $134: 66$ \\
Socioeconomic status-lower: higher & $172: 28$ \\
Years of education & $7.93 \pm 5.11(\mathrm{SD})$ years \\
Complexion-black: fair & $153: 47$ \\
Rural: urban & $177: 23$ \\
Profession-manual laborer: others & $45: 155$ \\
\hline SD $=$ Standard deviation
\end{tabular}

with pale palmar creases were tabulated in Table 2. Male:Female ratio was 121:79. Fifty patients had $\mathrm{Hb}$ level $<7 \mathrm{~g} / \mathrm{dL}$. One hundred and fifty patients had Hb level $\geq 7 \mathrm{~g} / \mathrm{dL}$. Palmar crease pallor was seen only in six patients with $\mathrm{Hb}<7 \mathrm{~g} / \mathrm{dL}$. No patients with $\mathrm{Hb} \geq 7 \mathrm{~g} / \mathrm{dL}$ had palmar creases looking similar pale color to surrounding skin. Patients with palmar crease pallor had average Hb level $4.05 \pm 0.82$ (SD) $g / d L$. Palmar crease pallor was found in very fair patients. None of them was black or laborer. Among the six patients four were from urban areas and two were from higher socioeconomic status. Among the six patients, three were female including one iron deficiency, one aplastic anemia and one chronic kidney disease patient.

Other clinical signs for predicting severe anemia like severe pallor of conjunctiva, tongue and nail-beds and presence of pulmonary ejection systolic murmur had variable sensitivity, specificity and likelihood ratio [Table 3]. Out of six cases of palmar crease pallor all six had severe pallor of conjunctiva, but only five cases had severe pallor on tongue and nail-bed.

\section{DISCUSSION}

Anemia is a common disorder and diagnosis of it can easily be done by Sahli's hemoglobinometer, or by electronic cell counters. However health-care workers use clinical assessment of pallor as a screening test for anemia especially in crowded out-patient clinics of public hospitals in resource poor countries where facility of immediate $\mathrm{Hb}$ testing is not available due to poor infrastructure or patient overload. Clinical assessment of severe anemia is important for urgent decision making for blood transfusion before laboratory values of $\mathrm{Hb}$ level become available. Most peripheral health centers in developing countries have no facility to determine $\mathrm{Hb}$ level even in high-risk groups like pregnant women; the decision on referral for blood transfusion or other definitive treatments should be made on clinical grounds. ${ }^{[6-9]}$ Different studies show relatively low sensitivity and high specificity of pallor of conjunctiva, tongue, palms and nailbeds for predicting the presence or the severity of anemia. . $^{[2,6,10-14]}$ Palmar pallor is very sensitive and specific for anemia in pediatric patients, but palmar creases are important for adults. ${ }^{[15,16]}$

In mild to moderate anemia pallor can be seen in conjunctiva, oral mucosa or nail-bed. In severe anemia additionally palmar creases may be looked as pale as the surrounding skin. Studies showed 


\begin{tabular}{|c|c|c|c|}
\hline \multirow{2}{*}{$\begin{array}{l}\text { Diseases (number of } \\
\text { patients) }\end{array}$} & \multicolumn{3}{|c|}{ Number of patients $(n=200)$} \\
\hline & $\begin{array}{c}\text { Severe anemia } \\
(\mathrm{Hb}<7 \mathrm{~g} / \mathrm{dL}) ; n=50\end{array}$ & $\begin{array}{c}\text { Mild-moderate anemia } \\
(\mathrm{Hb} \geq 7 \mathrm{~g} / \mathrm{dL}) ; n=150\end{array}$ & $\begin{array}{c}\text { Patients with pale palmar } \\
\text { creases; } n=6\end{array}$ \\
\hline Megaloblastic anemia (15) & 3 & 12 & \\
\hline Iron deficiency (83) & 15 & 68 & 1 (female) \\
\hline Aplastic anemia (16) & 6 & 10 & 2 (1 female: 1 male) \\
\hline CKD (22) & 10 & 12 & 2 (1 female: 1 male) \\
\hline Anemia of chronic disease (38) & 6 & 32 & \\
\hline Thalassemia (8) & 4 & 4 & 1 (male) \\
\hline Malignancy (6) & 2 & 4 & \\
\hline Leukemia (4) & 2 & 2 & \\
\hline Myelodysplasia (4) & 1 & 3 & \\
\hline Malabsorption (4) & 1 & 3 & \\
\hline
\end{tabular}

$\mathrm{CKD}=$ Chronic kidney disease, $\mathrm{Hb}=$ Hemoglobin

\begin{tabular}{|c|c|c|c|c|c|}
\hline Anatomical sites and findings & $\begin{array}{c}\text { Severe } \\
\text { anemia } \\
n=50\end{array}$ & $\begin{array}{c}\text { Mild/moderate } \\
\text { anemia } \\
n=150\end{array}$ & $\begin{array}{l}\text { Sensitivity } \\
\text { for severe } \\
\text { anemia (\%) }\end{array}$ & $\begin{array}{l}\text { Specificity } \\
\text { for severe } \\
\text { anemia (\%) }\end{array}$ & $\begin{array}{c}\text { Positive likelihood } \\
\text { ratio = Sensitivity/ } \\
\text { (1-specificity) }\end{array}$ \\
\hline Palmar creases pallor & 6 & 0 & 12 & $100^{*}$ & $>1200$ \\
\hline Conjunctiva-severe pallor & 42 & 6 & 84 & 96 & 21 \\
\hline Tongue-severe pallor & 44 & 10 & 88 & 93.33 & 13.19 \\
\hline Nail bed-severe pallor & 36 & 6 & 72 & 96 & 18 \\
\hline $\begin{array}{l}\text { Multiple sites-Severe pallor of any } \\
\text { one site }\end{array}$ & 48 & 15 & 96 & 90 & 9.6 \\
\hline Pulmonary ejection systolic murmur & 10 & 2 & 20 & 98.67 & 15.038 \\
\hline
\end{tabular}

*For calculating likelihood ratio specificity of $99.99 \%$ is used instead of $100 \%$. Specificity of $100 \%$ is not supported by online statistical calculator

significant correlation between $\mathrm{Hb}$ concentration and color tint of conjunctiva, nail-beds, oral mucosa and palmar creases and so presence and degree of anemia can be estimated. ${ }^{[3]}$ However, absence of pallor of above anatomic sites does not rule out anemia. ${ }^{[2]}$ Conjunctivitis, glossitis or dermatitis of hands may be misleading in clinical assessment of pallor.

Creases in palms normally are of deep color compared to surrounding skin due to wrinkling of skin. Pigmentation of creases is seen in Addison's disease, but hyper-pigmentation may also be normal in Asians and blacks and manual laborers. Sensitivity of palmar crease color to assess $\mathrm{Hb}$ level $<7 \mathrm{~g} / \mathrm{dL}$ by looking its similarity to surrounding skin is only $12 \%$ in our study. Palmar crease pallor is specific as it is never present in absence of severe anemia in our study. Sensitivity of pallor of palmar creases to detect severe anemia increases as the $\mathrm{Hb}$ concentration decreases. In our study, pale palmar creases were seen only in nonpigmented very fare patients. Hence in Indian perspective where people are darker in complexion than western countries, the value of assessing the palmar crease color to assess the severity of anemia is less. However when it is present, it will provide clinically a better assumption of $\mathrm{Hb}$ level. Similarly in a study lower sensitivity of palmar than conjunctival pallor was seen in Bangladesh due to increased palmar pigmentation. ${ }^{[17]}$

One study revealed that true-positive rates (sensitivities) of anemia were highest for pallor at the conjunctiva, face or palms and true- negative rates (specificities) for anemia were best for palmar creases. ${ }^{[2]}$ Palmar creases were of no value in assessing the absence of anemia. ${ }^{[2]}$ A separate study suggested tongue pallor for ruling in severe anemia instead of palmar crease pallor. ${ }^{[18]}$ The results were quite similar to our study as our study suggested that absence of palmar crease pallor does not rule out severe anemia and severe tongue pallor has highest sensitivity for severe anemia (88\%). Another study revealed that different pallor sites including conjunctiva, nail-bed and palm were equally useful for detecting severe anemia, however palmar creases were not mentioned specifically. ${ }^{[19]}$ In one study even in patients with the lowest $\mathrm{Hb}$ concentrations, the posttest probability of any pallor to detect anemia did not exceed $75 \%$, because patients judged severely pale did not necessarily have severe anemia. ${ }^{[1]}$ The relative performance of different anatomical sites was not consistent among the studies. Assessment of severe pallor on multiple anatomical sites improves the chance of detection of severe anemia. Because of its very low cost, feasibility and minimum time consumption, several anatomical sites may be assessed to maximize sensitivity. ${ }^{[14,20]}$ However, specificity and positive likelihood ratio is less with assessment of multiple anatomical sites.

Despite the traditional belief of palmar crease pallor supporting the clinical assessment of grade of anemia, our study revealed that color of the creases of palms is a poorly sensitive indicator of the severity of anemia. In severely anemic patients its sensitivity is only $12 \%$ but specificity is $100 \%$ and positive likelihood ratio is $>1200$. Physical diagnosis of absence of palmar crease pallor is not sufficient 
to exclude severe anemia. Others clinical clues of predicting severe anemia should be searched like severe pallor of conjunctiva, tongue, nail-beds and presence of pulmonary ejection systolic murmur. All of them are more sensitive but specificity is less. However, conjunctivitis, glossitis, onycholysis, use of nail polish and valvular or congenital heart diseases may prevent using these signs.

There are several limitations of our study. Our study has a relatively small sample size. Our study population does not represent the general population. Cut-off value of $\mathrm{Hb}$ level for severe anemia was lower in our study than WHO defined values of severe anemia. A large study is needed to establish the exact sensitivity and specificity of clinical signs in detecting severe anemia.

\section{CONCLUSION}

Although clinical signs like pallor for detection of anemia should not be discarded, it is important for health-care workers to know the level of accuracy of pallor in detecting the presence or severity of anemia. Special awareness is needed of poor sensitivity of palmar crease pallor for detecting severe anemia in our country, though it is highly specific. Other signs suggesting severe anemia should also be searched where facility of immediate $\mathrm{Hb}$ estimation is not available.

\section{REFERENCES}

1. Braden $C D$, Brenner BE. Chronic anemia clinical presentation. Available from: http://www.emedicine.medscape.com/article/780176clinical\#a0256. [Last accessed on 2014 Oct 15].

2. Nardone DA, Roth KM, Mazur DJ, McAfee JH. Usefulness of physical examination in detecting the presence or absence of anemia. Arch Intern Med 1990;150:201-4.

3. Strobach RS, Anderson SK, Doll DC, Ringenberg QS. The value of the physical examination in the diagnosis of anemia. Correlation of the physical findings and the hemoglobin concentration. Arch Intern Med 1988;148:831-2.

4. WHO. Haemoglobin concentrations for the diagnosis of anaemia and assessment of severity. Vitamin and Mineral Nutrition Information System. Geneva: World Health Organization; 2011. (WHO/NMH/NHD/MNM/11.1). Available from: http://www.who.int/vmnis/indicators/haemoglobin.Pdf. [Last accessed on 2014 Oct 15].

5. Attia J. Moving beyond sensitivity and specificity: Using likelihood ratios to help interpret diagnostic tests. Aust Prescr 2003;26:111-3.
6. Muhe L, Oljira B, Degefu H, Jaffar S, Weber MW. Evaluation of clinical pallor in the identification and treatment of children with moderate and severe anaemia. Trop Med Int Health 2000;5:805-10.

7. Weber MW, Kellingray SD, Palmer A, Jaffar S, Mulholland EK, Greenwood BM. Pallor as a clinical sign of severe anaemia in children: an investigation in the Gambia. Bull World Health Organ 1997;75 Suppl 1:113-8.

8. Zucker JR, Perkins BA, Jafari H, Otieno J, Obonyo C, Campbell CC. Clinical signs for the recognition of children with moderate or severe anaemia in western Kenya. Bull World Health Organ 1997;75 Suppl 1:97-102.

9. Vinnemeier CD, Schwarz NG, Sarpong N, Loag W, Acquah S, Nkrumah $B$, et al. Predictive value of fever and palmar pallor for $P$. falciparum parasitaemia in children from an endemic area. PLoS One 2012;7:e36678.

10. Sheth TN, Choudhry NK, Bowes M, Detsky AS. The relation of conjunctival pallor to the presence of anemia. J Gen Intern Med 1997;12:102-6.

11. Gjørup T, Bugge PM, Hendriksen C, Jensen AM. A critical evaluation of the clinical diagnosis of anemia. Am J Epidemiol 1986;124:657-65.

12. Hung OL, Kwon NS, Cole AE, Dacpano GR, Wu T, Chiang WK, et al. Evaluation of the physician's ability to recognize the presence or absence of anemia, fever, and jaundice. Acad Emerg Med 2000;7:146-56.

13. Wurapa FK, Bulsara MK, Boatin BA. Evaluation of conjunctival pallor in the diagnosis of anaemia. J Trop Med Hyg 1986;89:33-6.

14. Desai MR, Phillips-Howard PA, Terlouw DJ, Wannemuehler KA, Odhacha A, Kariuki SK, et al. Recognition of pallor associated with severe anaemia by primary caregivers in western Kenya. Trop Med Int Health 2002;7:831-9.

15. Yurdakök K, Güner SN, Yalçin SS. Validity of using pallor to detect children with mild anemia. Pediatr Int 2008;50:232-4.

16. Karnath BM. Anemia in the adult patient. Hosp Physician 2004;40:32-6.

17. Kalter HD, Burnham G, Kolstad PR, Hossain M, Schillinger JA, Khan NZ, et al. Evaluation of clinical signs to diagnose anaemia in Uganda and Bangladesh, in areas with and without malaria. Bull World Health Organ 1997;75 Suppl 1:103-11.

18. Kalantri A, Karambelkar M, Joshi R, Kalantri S, Jajoo U. Accuracy and reliability of pallor for detecting anaemia: a hospital-based diagnostic accuracy study. PLoS One 2010;5:e8545.

19. Butt Z, Ashfaq U, Sherazi SF, Jan NU, Shahbaz U. Diagnostic accuracy of "pallor" for detecting mild and severe anaemia in hospitalized patients. J Pak Med Assoc 2010;60:762-5.

20. Stoltzfus RJ, Edward-Raj A, Dreyfuss ML, Albonico M, Montresor A, Dhoj Thapa $M$, et al. Clinical pallor is useful to detect severe anemia in populations where anemia is prevalent and severe. $J$ Nutr 1999;129:1675-81.

How to cite this article: Santra G. Usefulness of examination of palmar creases for assessing severity of anemia in Indian perspective: A study from a tertiary care center. Int J Med Public Health 2015;5:169-72.

Source of Support: Nil, Conflict of Interest: None declared. 